
Revue Revue de l'histoire des religions
de Ihistoire des religions
$1 \mid 2019$
Corps, ascèse et extinction dans l'histoire du bouddhisme (Inde, Corée, Japon)

\title{
Bruno MAES, Les livrets de pèlerinage. Imprimerie et culture dans la France moderne
}

Rennes, Presses universitaires de Rennes (« Histoire »), 2016

Cyrille Dounot

\section{OpenEdition}

Journals

Édition électronique

URL : https://journals.openedition.org/rhr/9689

DOI : 10.4000/rhr.9689

ISSN : $2105-2573$

Éditeur

Armand Colin

Édition imprimée

Date de publication : 1 mars 2019

Pagination : 217-219

ISBN : 978-2-200-93230-5

ISSN : 0035-1423

Référence électronique

Cyrille Dounot, «Bruno MAEs, Les livrets de pèlerinage. Imprimerie et culture dans la France moderne»,

Revue de l'histoire des religions [En ligne], 1 | 2019, mis en ligne le 01 janvier 2021, consulté le 07 janvier 2022. URL : http://journals.openedition.org/rhr/9689 ; DOI : https://doi.org/10.4000/rhr.9689

Ce document a été généré automatiquement le 7 janvier 2022.

Tous droits réservés 


\section{Bruno MAES, Les livrets de pèlerinage. Imprimerie et culture dans la France moderne}

Rennes, Presses universitaires de Rennes (« Histoire »), 2016

Cyrille Dounot

\section{RÉFÉRENCE}

Bruno MAES, Les livrets de pèlerinage. Imprimerie et culture dans la France moderne, Rennes, Presses universitaires de Rennes («Histoire »), 2016, 340 p., 24 cm, $23 €$, ISBN

978-2-7535-4908-1.

1 Bruno Maes, maître de conférences en histoire moderne à l'université de Lorraine, livre au public son mémoire d'habilitation à diriger des recherches, soutenu à Lyon II en 2013. La préface de Philippe Martin, à qui nous devons une excellente synthèse récente sur le fait pèlerin (Pèlerins, $\mathrm{XV}^{e}-\mathrm{XXI} \mathrm{e}^{e}$ siècle, Paris, CNRS Éditions, 2016), met d'emblée en garde contre les poncifs historiques balayés par cette étude, à commencer par celui d'un fidèle catholique qui «ne lit pas [...]. Depuis des décennies, ce cliché fait des ravages, opposant deux Europes, deux manières de vivre sa religion » (p. 11). L'ouvrage est fort sérieux, appréhendant son objet d'étude avec la plus grande rigueur, sans tomber ni dans le mépris ou la moquerie (par exemple au sujet des reliques douteuses, p. 26), ni dans la flagornerie ou la crédulité. Un long premier chapitre s'attache à " définir un objet historique », et vient répondre aux vœux de Roger Chartier, Philippe Martin ou Francis Rapp. Cet objet, c'est le livre, plus précisément le livret de pèlerinage (p. 43). Pour ce faire, l'auteur a réuni un corpus impressionnant de 596 textes, portant sur 216 lieux de pèlerinage, de 1480 à 1790. Si l'on ne peut que déplorer un certain tropisme géographique (Nord et Est de la France), il est indéniable qu'un tel travail ne saurait prétendre à l'exhaustivité, même limitée aux contenus des bibliothèques publiques. L'auteur s'en explique d'ailleurs en conclusion, avec deux exemples choisis à 
dessein : le Rouergue, avec ses 63 reliques de saint Blaise, ne laisse aucun livret; la Lorraine, riche de 800 pèlerinages, n'en donne que vingt (p. 261).

2 L'auteur distingue deux types de livrets, répondant à deux types de culture : la culture humaniste et la culture partagée (p.107), tout en soulignant que certains auteurs, à l'imitation de Mathurin Des Roys, mêlent les deux cultures (p. 119-120). Il met en avant le rôle important que tient le miracle dans la dévotion des fidèles au lieu de pèlerinage, et conséquemment, dans le livret qui l'accompagne. Le souci de la conversion intérieure est une constante des livrets, et en cela ils sont fidèles au programme de Contre-Réforme (p. 123-124). Dans ce chapitre abordant les questions économiques, l'auteur donne le prix de fabrication et de vente des livrets, qui restent des ouvrages bon marché, destinés à être diffusés massivement - certains tirages uniques dépassent les 6000 exemplaires (p. 136-137).

3 L'apport majeur de ce livre est de montrer que la lecture est ici synonyme du passage à une religion intériorisée (p. 141), héritage de la devotio moderna qui s'ancre dans l'écrit. D’ailleurs, la langue vernaculaire est utilisée presque exclusivement (p.171-172), ce qui facilite le processus d'intériorisation. L'auteur discerne trois périodes marquées par des traits communs généraux. À l'ère du livret flamboyant (1480-1560), succède une nouvelle culture, qui se caractérise par l'abandon du merveilleux au profit du rationnel, ou du plus rationnel, plus objectif, bien que l'on puisse relever la « relative immobilité de la religion des pèlerins » (p. 176). La deuxième ère, "des temps de controverse » (1560-1660), se caractérise par une modification esthétique des livrets, notamment typographique (p.179), et de leur contenu. Une certaine épuration vient ôter des restes de superstition (p. 200). C'est une "conquête de l'espace" qui s'opère par l'authentification des reliques et des miracles, contre l'iconoclasme protestant (p. 188). En témoigne l'apparition d'un apparat critique dans ces livrets (p. 202), qui en fait « un outil rationnel au service de la réforme catholique» (p. 213). C'est aussi une ère marquée par le regain d'intérêt des élites, et de la Cour, pour le pèlerinage. On voit alors dans ces livrets « un aspect identitaire qui défend la culture des catholiques, et un aspect de réforme de la culture religieuse » (p. 218). Le troisième temps dégagé par l'auteur est celui de "l'aventure spirituelle personnelle», où la piété se fait plus discrète, plus intime. Le livret sert d'accompagnateur, notamment pour une retraite spirituelle, et joue un rôle auxiliaire du prêtre, dont la tâche spirituelle est mise en avant (p.232). Il répand la dévotion à l'eucharistie au XvIII ${ }^{\mathrm{e}}$ siècle, et sert d'«accélérateur de la modernité, car il diffuse un sentiment personnel» (p. 266). L'ouvrage se termine par une bibliographie complète de plus de 60 pages, doublée d'un fort utile index des lieux de pèlerinage.

4 Malgré ces aspects positifs, le lecteur sera gêné par quelques assertions trop rapides de l'introduction, quelques raccourcis ou affirmations dont il peine à saisir l'intérêt. Pourquoi un renvoi systématique du pèlerinage à la "pensée mythique » (p. 17), à un «temps mythique » (p. 40), aux "récits mythiques» (p. 43), aux " contes mythiques » (p. 44) ? Si la legenda peut être suspecte, le fait pèlerin lui-même n'a rien d'imaginaire ou de magique, et le pèlerinage n'a pas forcément une origine «irrationnelle » qui «devient une transmutation » (p. 19). Pourquoi limiter les raisons du pèlerinage à une quête ou une initiation (p.18), sans parler du vœu, de la pénitence ou de la sanctification du pèlerin? Pourquoi faire de dom Mabillon un anti-scolastique (p. 229), alors qu'il érige saint Thomas en référence (notamment pour la morale) et déplore la dégénérescence des scolastiques qui lui ont succédé (Traité des études monastiques, II, 6) ? 
Le phénomène des indulgences est surestimé, en comparaison du baptême qui efface les péchés (p. 25). D'autres éléments pèchent par défaut. Sur la question du toucher des reliques (p. 29), l'auteur ne dit rien du mouvement de rationalisation entrepris dès le canon 62 du concile de Latran IV, et de leur mise à distance (hors toucher). Concernant les « miracles » du diacre Pâris (p. 34), l'auteur tait les condamnations épiscopales de ce merveilleux janséniste, rangé à tort dans le catholicisme orthodoxe. Quand l'auteur évoque un « univers culturel basé sur la magie, c'est-à-dire sur l'efficacité du geste en lui-même » (p. 35), on est plutôt porté à y voir la théologie catholique du sacrement, signe sensible agissant ex opere operato.

Une autre tendance de l'auteur est de s'approprier massivement le concept de « recharges sacrales » ou " recharge en sacralité » (p. 40, 64, 106, 129, 183, 188, 225, 261 , etc.), qui devient pesante à force d'usage, et dilue le contenu de cette notion inventée par Alphonse Dupront. Le concept explique même la production des livrets, devenant une des «causes ordinaires de l'écriture» (p.122), qui «rend les miracles plus fréquents » (p. 181) et rend raison de la traduction des livrets anciens (p. 198). En définitive, et malgré ces réserves, voilà un travail fort judicieux et neuf, qui contient des descriptions très intéressantes, dont l'axiomatisation est parfois hasardeuse. Espérons, avec le préfacier, qu'il vienne mettre fin à l'image fausse bien que répandue du fidèle catholique quasi-analphabète.

\section{AUTEURS}

\section{CYRILLE DOUNOT}

Université Clermont Auvergne, Clermont-Ferrand. 